\title{
Association between hyperpyrexia and poststroke outcomes in patients with recanalization after mechanical thrombectomy: a retrospective cohort study
}

Man Chen ${ }^{1+}$, Jinghuan Fang ${ }^{1+}$, Xintong $\mathrm{Wu}^{1}$, Qin $\mathrm{Liu}^{2}$, Ling Feng ${ }^{2^{*}}$ and $\mathrm{Li} \mathrm{He}^{1^{*}}$

\begin{abstract}
Background: Limited data are available for evaluating the relationship between the prognosis and body temperature (BT) in patients treated with mechanical thrombectomy (MT), especially in those with successful recanalization. We aimed to explore the prognostic value of BT in predicting outcomes of stroke recovery at 3 months poststroke.

Methods: We retrospectively analyzed the relationship among BT levels as a continuous variable, with fever (BT $\geq$ $37.5^{\circ} \mathrm{C}$ ) as a binary variable, and obtained several outcomes of interest. Subjects were stratified according to successful recanalization (thrombolysis in cerebral infarction scores of 2b-3) following MT. Functional independence was defined as a modified Rankin scale (mRS) score of $0-2$.

Results: In total, 258 patients were included. The proportion of patients with functional independence was significantly lower among patients with $\mathrm{BT} \geq 37.5^{\circ} \mathrm{C}$ than among those with $\mathrm{BT}<37.5^{\circ} \mathrm{C}(45.3 \%$ versus $23.0 \%$; $P<$ 0.001). In the multivariate analysis, hyperpyrexia (especially $B T \geq 38{ }^{\circ} \mathrm{C}$ ) was significantly associated with poor $3-$ month outcomes in patients treated with MT. Subgroup analysis was conducted by comparing the successful recanalization group with the non-recanalization group, showing that $\mathrm{BT} \geq 37.5^{\circ} \mathrm{C}$ was associated with a significantly lower proportion of functional independence in the recanalized patients. Besides, the Kaplan-Meier model showed that the fever group had significantly lower survival rates than the non-fever group during the 3month follow-up.
\end{abstract}

Conclusions: In patients treated with MT, hyperpyrexia is an independent predictor of poststroke outcomes at 3 months, particularly in those with successful recanalization.

Keywords: Hyperpyrexia, Mechanical thrombectomy, Recanalization, Acute ischemic stroke

\footnotetext{
*Correspondence: fengling216@163.com; heli2003new@126.com

${ }^{+}$Man Chen and Jinghuan Fang contributed equally to this work as the first authors.

${ }^{2}$ Department of Neurology, West China Hospital, Sichuan University/West China School of Nursing, Sichuan University, 610041 Chengdu, China 'Department of Neurology, West China Hospital, Sichuan University, 610041 Chengdu, China
}

(c) The Author(s). 2021, corrected publication 2021. Open Access This article is licensed under a Creative Commons Attribution 4.0 International License, which permits use, sharing, adaptation, distribution and reproduction in any medium or format, as long as you give appropriate credit to the original author(s) and the source, provide a link to the Creative Commons licence, and indicate if changes were made. The images or other third party material in this article are included in the article's Creative Commons licence, unless indicated otherwise in a credit line to the material. If material is not included in the article's Creative Commons licence and your intended use is not permitted by statutory regulation or exceeds the permitted use, you will need to obtain permission directly from the copyright holder. To view a copy of this licence, visit http://creativecommons.org/ licenses/by/4.0/. The Creative Commons Public Domain Dedication waiver (http://creativecommons.org/publicdomain/zero/1. 0/) applies to the data made available in this article, unless otherwise stated in a credit line to the data. 


\section{Background}

Stroke remains a significant cause of morbidity and mortality throughout the world, and acute ischemic stroke (AIS) makes up the vast majority of stroke cases [1]. Early recanalization is the main target of treatment for AIS and is associated with good clinical outcomes at 3 months [2]. Recent randomized controlled clinical trials (RCTs) have provided overwhelming evidence of the efficacy and safety of mechanical thrombectomy (MT) [3-5]. Nevertheless, after MT, approximately $54 \%$ of patients are still unable to achieve functional independence within 3 months, and approximately $15 \%$ of patients die within this timespan [6, 7]. These data show that factors other than recanalization status also play an important role in the prognosis of MT.

Body temperature (BT) is an important index and modifier of pathophysiologic events in AIS, and fever is a common symptom in AIS patients [8]. Hypothermia is considered to have a neuroprotective effect and to be a potential treatment in cerebral ischemia. Animal studies suggest that mild hypothermia therapy could reduce inflammation in brain tissue and improve outcomes after ischemic stroke [9]. However, a multicenter RCT showed that surface mild hypothermic treatment did not benefit AIS patients because of complications associated with hypothermia, such as infectious pneumonia. Geurts also pointed out that the effects of recanalization factors on patient outcomes were not considered, and the effects of mild hypothermia therapy are different in patients with different recanalization statuses of large intracranial vessels, such as non-recanalization and successful recanalization [10]. Although a number of studies have already proven the correlation between BT and clinical outcomes in AIS patients treated with intravenous thrombolysis $[11,12]$, studies evaluating the effect of BT levels on the outcomes of patients treated with MT are scarce. Considering that the successful recanalization rate with MT is higher than that with intravenous thrombolysis $[13,14]$ and that a certain incidence of reocclusion still occurs after MT, it is necessary to conduct a study based on different recanalization statuses of patients.

The aim of the study was to determine whether BT levels have different effects on poststroke recovery in patients treated with MT during the first 3 months poststroke, especially in those with or without successful recanalization. It was hypothesized that hyperpyrexia would be associated with poorer clinical outcomes poststroke. Hence, we conducted this retrospective study on the effect of BT values on functional and survival outcomes in AIS patients treated with MT, and subgroup analysis was performed for different recanalization statuses.

\section{Methods}

\section{Study Design and Patient Selection}

We conducted a retrospective analysis of a hospitalbased prospective database from September 2015 to September 2019 comprising patients (age $\geq 18$ years) with acute ischemic stroke due to large vessel occlusion (LVO) who were treated with MT. The following patients were excluded: (1) patients with a pre-modified Rankin scale (mRS) score $>1$; (2) patients with severe circulatory or respiratory failure or malignant tumor; (3) patients who could not fulfill the 3-month follow-up; and (4) patients with infection at admission. To exclude the influence of infection, we recorded documented evidence of infection at baseline, including physical examination, the white blood cell (WBC) count, procalcitonin level, the erythrocyte sedimentation rate, $\mathrm{C}$-reactive protein (CRP), urinalysis, urine culture, and chest radiography, as in a previous study [15]. If any signs of infection were positive, we excluded the patient (Fig. 1). Patients underwent a nonenhanced computerized tomography (CT) head scan to exclude hemorrhage and MR imaging or CT angiography (CTA) to establish the arterial territory using standard criteria $[16,17]$. There were no restrictions on neurological severity. The protocol was approved by the Ethics Committee of West China Hospital, Sichuan University.

\section{Temperature Measurement}

The baseline BT was defined as the body temperature at admission. Temperatures were measured by an infrared ear thermometer upon admission and every $2 \mathrm{~h}$ for $24 \mathrm{~h}$ after MT. The peak BT value was defined as the highest value within $24 \mathrm{~h}$, and we defined fever as a $\mathrm{BT} \geq 37.5^{\circ} \mathrm{C}$ [18]. Patients were divided into two groups according to whether they had a fever within $24 \mathrm{~h}$.

\section{Data Collection and Definition}

For each patient, we recorded the pre-stroke functional status using the mRS score and the history of stroke risk factors: systolic and diastolic blood pressure (SBP and DBP); the presence of diabetes mellitus (DM); atrial fibrillation and smoking. Vital signs and laboratory parameters at baseline before MT, the stroke cause according to the Trial of ORG 10,172 in Acute Stroke Treatment (TOAST) classification, the length of stay, intravenous thrombolysis, infection and/or antibiotic use were also recorded. Neurologists determined the National Institute of Health Stroke Scale (NIHSS) scores at admission, $24 \mathrm{~h}$ after MT and discharge to assess changes in stroke severity. The Alberta Stroke Program Early CT Score (ASPECTs) was used to assess the size of the baseline infarct size [19].

Functional outcomes were assessed by mRS scores at 3 months after the onset of symptoms. An mRS score of 


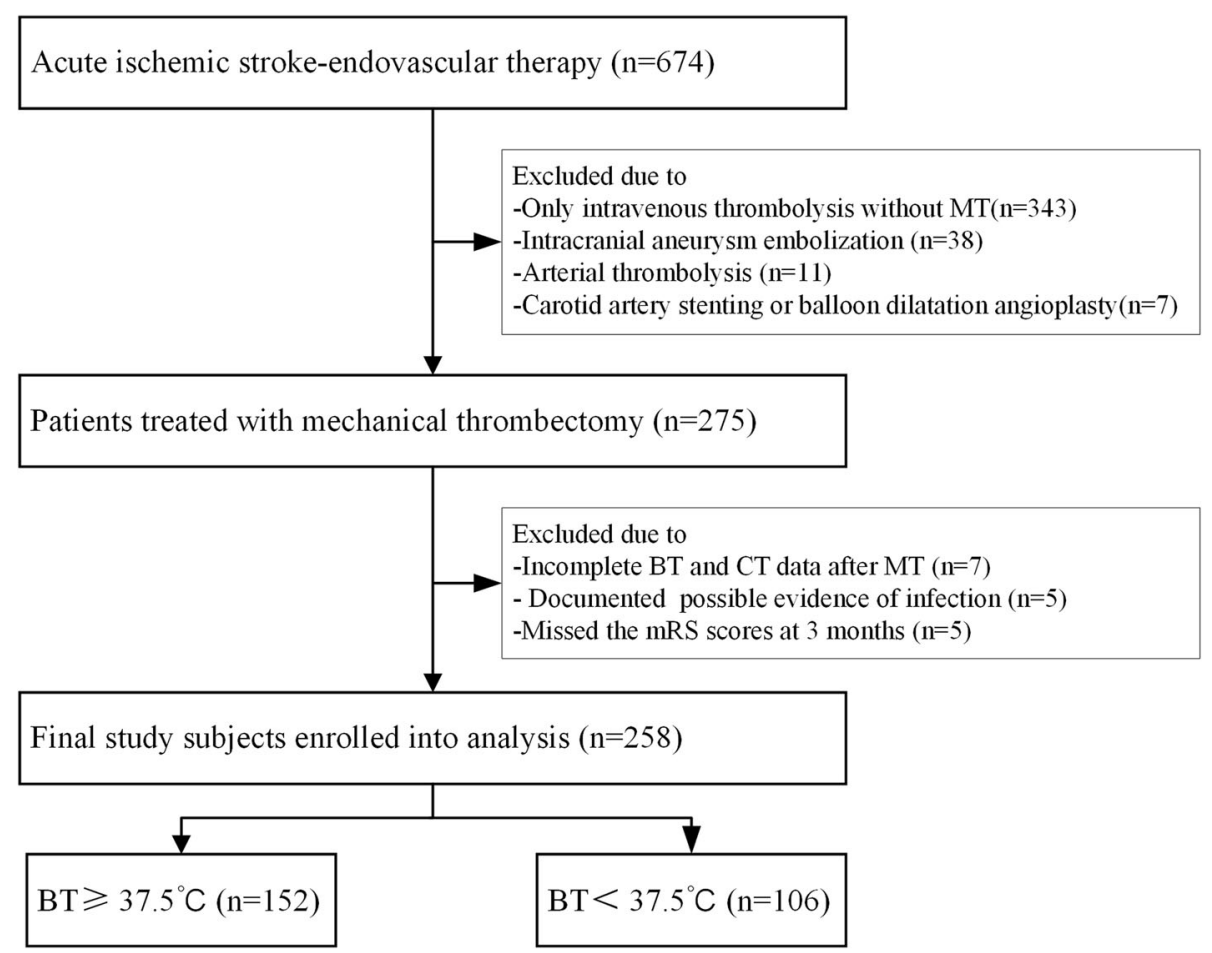

Fig. 1 Flow chart of study cohort selection. BT, body temperature; mRS, modified Rankin Scale; MT, mechanical thrombectomy

0-2 was defined as a favorable outcome (functional independence), and a score of 0-1 was defined as an excellent outcome. The mRS scores were assessed by outpatient follow-up or telephone follow-up at 3 months. We obtained anesthesia type (general anesthesia or local anesthesia), procedure time, number of devices passes, and thrombolysis in cerebral infarction (TICI) scores to grade the degree of reperfusion from the reports of specialists at the end of MT. A TICI score of $2 \mathrm{~b}-3$ was defined as successful recanalization, and a score of 3 was defined as complete recanalization [20]. Symptomatic intracranial hemorrhage ( $\mathrm{sICH}$ ) was defined as any intraparenchymal, subarachnoid, or intraventricular hemorrhage on post-procedural CT that was associated with $\mathrm{a} \geq 4$-point increase in the NIHSS score according to the ECASS criteria [21]. HT was defined according to the ECASS criteria. HI1 was defined as a small petechiae hemorrhagic lesion along the margins of the infarct, and HI2 was defined as the internal fusion of the infarct into a patch of bleeding in the absence of a space-occupying effect. PH1 was defined as a hematoma area $\leq 30 \%$ with a slight space-occupying effect, and PH2 was a hematoma area $>30 \%$ with a significant space-occupying effect or hemorrhage in the remote infarcted area [21]. Early clinical improvement was defined as an improvement of $\geq 4$ points in the NIHSS score at $24 \mathrm{~h}$ after onset compared with the score at admission or the disappearance of neurological function impairment (NIHSS 0-1) [22]. Early neurological deterioration was defined as an increase of $\geq 4$ points in the total NIHSS score compared with the baseline value [23].

\section{Outcome Evaluation}

Outcomes were evaluated in two ways. The primary outcomes included favorable outcomes and excellent outcomes. Mortality in the hospital and at 3 months, intracranial hemorrhage transformation (HT), sICH, early clinical improvement, and early neurological deterioration represented the secondary outcomes.

\section{Statistical Analysis}

Continuous variables were summarized as the mean \pm SD (normal distribution) or as the median with interquartile range (IQR) (non-normal distribution) and compared using an independent-samples $t$ test, MannWhitney $\mathrm{U}$ test, or the non-parametric Kruskal-Wallis $\mathrm{H}$ test, as indicated. We described the categorical variables as numbers (n) with a percentage (\%) and analyzed the significant differences between 2 and 3 groups by the $x^{2}$ test or Fisher's exact test in the case of small, expected frequencies.

We constructed multivariable logistic regression models to assess the odds ratios (ORs) and corresponding $95 \%$ CIs to evaluate the association between BT levels and 3-month functional outcomes, in-hospital and 3-month mortality, HT, sICH, early clinical 
improvement, and early neurological deterioration before and after adjusting for the following potential confounders based on their clinical significance and prior studies: age, sex, length of stay, NIHSS score at baseline, atrial fibrillation, smoking, serum glucose level, SBP, WBC, procedure time, successful recanalization and number of devices passes. We used the Bonferroni correction method to assess the primary and secondary outcomes, with a $P$-value $<0.05 /$ number of comparisons as the threshold for statistical significance [24].

Subgroup analysis for heterogeneity of the BT effect was performed, with subgroups defined according to age, NIHSS score at baseline, number of devices passes, thrombolysis before MT, and successful recanalization. Moreover, we further analyzed the effect of BT levels on different recanalization statuses after MT and survival rates. Data analysis was performed with IBM SPSS version 25.0 (IBM corporation, Armonk, NY) and R software version 3.6.2 ( $\mathrm{R}$ Foundation for Statistical Computing, Vienna, Austria). All $P$ values presented were two-sided, and statistical significance was accepted if $P<0.05$.

\section{Results}

\section{Baseline characteristics}

In total, 258 consecutive patients (mean age $66.6 \pm$ 14.4 years, $57.4 \%$ men) were enrolled in the final study analysis (Fig. 2). The median NIHSS score was 17 points [IQR 13-22]. Of these cases, 249 (96.5\%) were treated within $6 \mathrm{~h}$ of symptom onset. The number of patients treated with MT more than $6 \mathrm{~h}$ after onset was $9(3.5 \%)$, with an average of $10.2 \mathrm{~h}$. The associations between the peak BT levels within $24 \mathrm{~h}$ and the clinical characteristics are summarized in Table 1. Among 258 patients, 67 patients had internal carotid artery occlusions (26.0\%), 134 had middle cerebral artery occlusions (51.9\%), and 20 patients had tandem occlusions (7.8\%). The remaining patients had posterior circulation occlusions $(14.3 \%)$.

In our study, 7 patients $(2.7 \%)$ underwent MT using a combination of distal aspiration and stent retrieval, 5 patients $(1.9 \%)$ were treated with the distal aspiration technique, and 246 patients (95.3\%) underwent stent

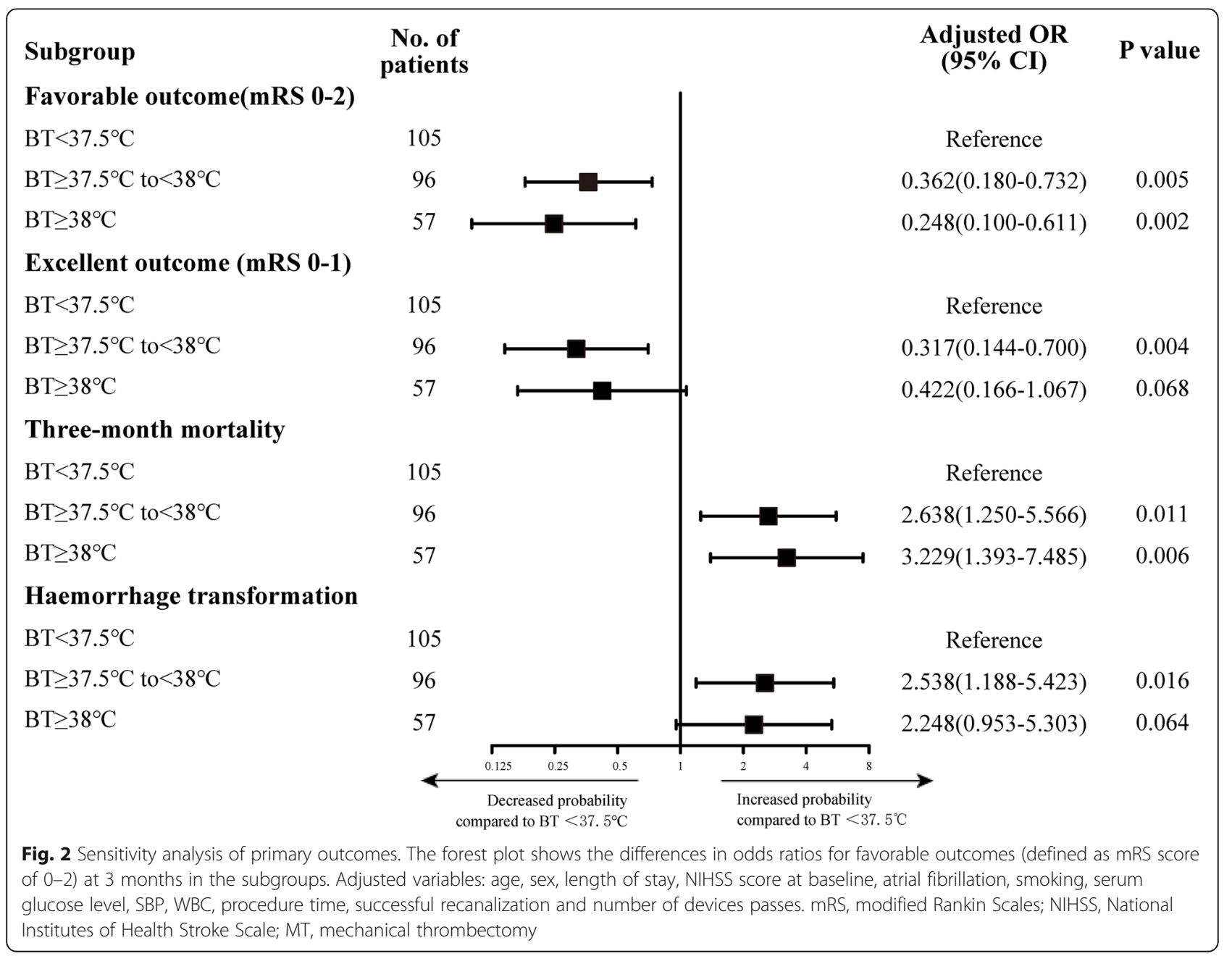


Table 1 Patients characteristics

\begin{tabular}{|c|c|c|c|c|}
\hline \multirow[t]{2}{*}{ Parameter } & All patients & BT $<37.5^{\circ} \mathrm{C}$ & BT $\geq 37.5^{\circ} \mathrm{C}$ & \multirow[t]{2}{*}{$P$ value ${ }^{*}$} \\
\hline & $(n=258)$ & $(n=106)$ & $(n=152)$ & \\
\hline \multicolumn{5}{|l|}{ Demographic characteristics } \\
\hline Age, mean (SD) & $66.6(14.4)$ & $66.7(14.0)$ & $66.6(14.7)$ & 0.960 \\
\hline Sex, male, n (\%) & $148(57.4)$ & $64(60.4)$ & $84(55.3)$ & 0.414 \\
\hline \multicolumn{5}{|l|}{ History of risk factors, n (\%) } \\
\hline Hypertension & 133(51.6) & $58(54.7)$ & $75(49.3)$ & 0.395 \\
\hline Diabetes mellitus & $68(26.4)$ & $26(24.5)$ & $42(27.6)$ & 0.578 \\
\hline Smoking & $85(32.9)$ & $33(31.1)$ & $52(34.2)$ & 0.605 \\
\hline Drinking & $63(24.4)$ & 25(23.6) & $38(25.0)$ & 0.795 \\
\hline Dyslipidemia & $16(6.2)$ & $4(3.8)$ & $12(7.9)$ & 0.177 \\
\hline Previous stroke or TIA & $37(14.3)$ & 13(12.3) & 24(15.8) & 0.427 \\
\hline Atrial fibrillation & $142(55.0)$ & 63(59.4) & $79(52.0)$ & 0.236 \\
\hline \multicolumn{5}{|c|}{ Vital signs and laboratory parameters at baseline, mean (SD) } \\
\hline Systolic blood pressure, $\mathrm{mm} \mathrm{Hg}$ & $142.0(26.0)$ & $141.6(25.5)$ & $142.2(26.4)$ & 0.868 \\
\hline Diastolic blood pressure, $\mathrm{mm} \mathrm{Hg}$ & $81.8(13.9)$ & $81.1(12.8)$ & $82.3(14.8)$ & 0.489 \\
\hline Serum glucose, $\mathrm{mmol} / \mathrm{L}$ & $8.3(3.0)$ & $7.8(2.2)$ & $8.6(3.5)$ & 0.052 \\
\hline Total cholesterol, mmol/L & 4.1(1.0) & $4.0(1.0)$ & $4.2(1.0)$ & 0.097 \\
\hline $\mathrm{LDL}-\mathrm{C}, \mathrm{mmol} / \mathrm{L}$ & 2.4(0.8) & 2.4(0.8) & $2.5(0.8)$ & 0.382 \\
\hline Triglyceride, mmol/L & $1.5(1.0)$ & $1.4(0.8)$ & 1.6(1.2) & 0.095 \\
\hline $\mathrm{HDL}-\mathrm{C}, \mathrm{mmol} / \mathrm{L}$ & $1.3(0.4)$ & $1.2(0.4)$ & $1.3(0.4)$ & 0.106 \\
\hline Creatinine, $\mu \mathrm{mol} / \mathrm{L}$ & $78.0(25.5)$ & $81.1(27.7)$ & $75.8(23.6)$ & 0.097 \\
\hline Platelet count, $\times 10^{9} / \mu \mathrm{L}$ & $172.1(66.6)$ & $173.9(73.1)$ & $170.8(62.0)$ & 0.723 \\
\hline White blood cell count, $\times 10^{9} / \mu \mathrm{L}$ & $8.3(3.0)$ & $8.2(3.0)$ & $9.1(3.4)$ & 0.043 \\
\hline Pre-MT BT $\left({ }^{\circ} \mathrm{C}\right)$ & $36.4(0.27)$ & $36.5(0.24)$ & $36.5(0.29)$ & 0.188 \\
\hline Arterial territory, $\mathrm{n}(\%)$ & & & & 0.091 \\
\hline ICA occlusion & $67(26.0)$ & $23(21.7)$ & $44(28.9)$ & \\
\hline MCA occlusion & 134(51.9) & $65(61.3)$ & $69(45.4)$ & \\
\hline Tandem occlusion & $20(7.8)$ & $6(5.7)$ & $14(9.2)$ & \\
\hline Posterior circulation occlusion & $37(14.3)$ & 12(11.3) & $25(16.4)$ & \\
\hline TOAST classification, n (\%) & & & & 0.427 \\
\hline Large-artery atherosclerosis & $93(36.0)$ & $37(34.9)$ & $56(36.8)$ & \\
\hline Cardio-embolism & $132(51.2)$ & $52(49.1)$ & $80(52.6)$ & \\
\hline Undetermined etiology & $33(12.8)$ & 17(16.0) & 16(10.5) & \\
\hline Anesthesia type, n (\%) & & & & 0.241 \\
\hline General anesthesia & $222(86.0)$ & $88(83.0)$ & 134(88.2) & \\
\hline Local anesthesia & $36(14.0)$ & 18(17.0) & 18(11.8) & \\
\hline Procedure time, min, mean (SD) & $98.3(44.0)$ & $90.7(37.3)$ & 103.6(47.5) & 0.020 \\
\hline $\begin{array}{l}\text { NIHSS score at baseline, median } \\
\text { (IQR) }\end{array}$ & $17(13-22)$ & $11(13-23)$ & $16(11-20)$ & 0.014 \\
\hline ASPECTS, median (IQR) & $9(7-10)$ & $9(8-10)$ & $8(7-10)$ & 0.157 \\
\hline Length of stay, day, median (IQR) & $11(6-17)$ & 16(11-20) & $11(4-18)$ & 0.600 \\
\hline
\end{tabular}


Table 1 Patients characteristics (Continued)

\begin{tabular}{|c|c|c|c|c|}
\hline \multirow[t]{2}{*}{ Parameter } & All patients & BT $<37.5^{\circ} \mathrm{C}$ & BT $\geq 37.5^{\circ} \mathrm{C}$ & \multirow[t]{2}{*}{$P$ value } \\
\hline & $(n=258)$ & $(n=106)$ & $(n=152)$ & \\
\hline $\begin{array}{l}\text { Number of devices passes, mean } \\
\text { (SD) }\end{array}$ & $2.5(1.5)$ & $2.4(1.5)$ & $2.7(1.5)$ & 0.086 \\
\hline Successful recanalization ${ }^{a}, \mathrm{n}(\%)$ & 191(74.0) & $88(83.0)$ & 103(67.8) & 0.006 \\
\hline Intravenous thrombolysis, n (\%) & $70(27.1)$ & $33(31.1)$ & $37(24.3)$ & 0.228 \\
\hline
\end{tabular}

Values were measured for the peak body temperature within $24 \mathrm{~h}$ following mechanical thrombectomy

Abbreviations: TIA transient ischemic attack; $L D L-C$ low-density lipoprotein cholesterol; $H D L-C$ high-density lipoprotein cholesterol; ICA internal carotid artery; MCA middle cerebral artery; TOAST trial of ORG 10,172 in acute stroke treatment; NIHSS National Institutes of Health Stroke Scale; TICI thrombolysis in cerebral infarction; ASPECS Alberta Stroke Program Early CT Score; MT mechanical thrombectomy

${ }^{*}$ Continuous variables were compared between groups using independent samples $t$ tests, Mann-Whitney $\mathrm{U}$ tests, or Kruskal-Wallis $\mathrm{H}$ tests. Categorical variables were analyzed by $x^{2}$ test, or Fisher's exact tests as appropriate

${ }^{\mathrm{a}}$ Successful recanalization indicates the $\mathrm{TICl}$ score of $2 \mathrm{~b}-3$

retrieval without distal aspiration, which was the most common technique. Seventy $(27.1 \%)$ patients underwent intravenous thrombolysis before MT. Successful recanalization was achieved in $74.0 \%$ of the study population $(\mathrm{n}=191)$. After excluding the patients with clinical evidence diagnosed as infection, there were only 3 patients whose $\mathrm{BT}$ was $\geq 37.5^{\circ} \mathrm{C}$, of which two cases were $37.5^{\circ} \mathrm{C}$ and one case was $38.4^{\circ} \mathrm{C}$ on admission. Within $24 \mathrm{~h}$ after $\mathrm{MT}$, the median maximum $\mathrm{BT}$ was $37.6{ }^{\circ} \mathrm{C}$. According to BT levels within $24 \mathrm{~h}$ post MT, patients were divided into a fever group $(\mathrm{n}=152 ; 58.9 \%)$ and a non-fever group ( $\mathrm{n}=106 ; 41.1 \%)$. Compared with the non-fever group, the fever group had higher baseline NIHSS scores $(P=0.014)$, lower rates of successful recanalization $(P=$

Table 2 Association between high body temperature levels $\left(B T \geq 37.5^{\circ} \mathrm{C}\right)$ and outcomes

\begin{tabular}{|c|c|c|c|c|c|c|}
\hline \multirow[t]{2}{*}{ Clinical Outcomes } & \multirow{2}{*}{$\frac{\mathrm{BT}<37.5^{\circ} \mathrm{C}}{(n=106), \mathrm{n}(\%)}$} & \multirow{2}{*}{$\begin{array}{l}\mathrm{BT} \geq 37.5^{\circ} \mathrm{C} \\
(n=152), \mathrm{n}(\%)\end{array}$} & \multirow{2}{*}{$\begin{array}{l}\text { Crude OR } \\
(95 \% \mathrm{Cl})\end{array}$} & \multirow[t]{2}{*}{$P$ value } & \multirow{2}{*}{$\begin{array}{l}\text { Adjusted } \mathrm{OR}^{\dagger} \\
(95 \% \mathrm{Cl})\end{array}$} & \multirow[t]{2}{*}{$P$ value $^{\ddagger}$} \\
\hline & & & & & & \\
\hline \multicolumn{7}{|l|}{ Primary outcomes at 3 months } \\
\hline $\mathrm{mRS}, 0-2$ & $48(45.3)$ & $35(23.0)$ & $\begin{array}{l}0.361 \\
(0.211-0.619)\end{array}$ & $<0.001$ & $\begin{array}{l}0.384 \\
(0.201-0.733)\end{array}$ & 0.004 \\
\hline $\mathrm{mRS}, 0-1$ & 33(31.1) & $21(13.8)$ & $\begin{array}{l}0.355 \\
(0.191-0.658)\end{array}$ & 0.001 & $\begin{array}{l}0.404 \\
(0.200-0.817)\end{array}$ & 0.012 \\
\hline \multicolumn{7}{|l|}{ Secondary outcomes } \\
\hline In-hospital mortality & $5(4.7)$ & 24(15.8) & $\begin{array}{l}3.787 \\
(1.396-10.277)\end{array}$ & 0.009 & $\begin{array}{l}2.796 \\
(0.910-8.593)\end{array}$ & 0.073 \\
\hline Three-month mortality & 18(17.0) & $61(40.1)$ & $\begin{array}{l}3.277 \\
(1.795-5.983)\end{array}$ & $<0.001$ & $\begin{array}{l}3.087 \\
(1.552-6.135)\end{array}$ & 0.001 \\
\hline $\mathrm{HT}$ & $43(40.6)$ & $73(48.0)$ & $\begin{array}{l}1.354 \\
(0.820-2.236)\end{array}$ & 0.236 & $\begin{array}{l}1.275 \\
(0.746-2.178)\end{array}$ & 0.375 \\
\hline HI1 & $8(7.5)$ & $5(3.3)$ & & & & \\
\hline $\mathrm{HI} 2$ & $6(5.7)$ & $11(7.2)$ & & & & \\
\hline $\mathrm{PH} 1$ & $5(4.7)$ & $6(3.9)$ & & & & \\
\hline $\mathrm{PH} 2$ & 21(19.8) & $44(28.9)$ & & & & \\
\hline SAH/remote HT & $3(2.8)$ & $7(4.6)$ & & & & \\
\hline $\mathrm{slCH}$ & $15(14.2)$ & $41(27.0)$ & $\begin{array}{l}2.241 \\
(1.166-4.306)\end{array}$ & 0.015 & $\begin{array}{l}2.357 \\
(1.176-4.723)\end{array}$ & 0.016 \\
\hline Early clinical improvement & $62(58.2)$ & $41(27.0)$ & $\begin{array}{l}0.262 \\
(0.155-0.444)\end{array}$ & $<0.001$ & $\begin{array}{l}0.260 \\
(0.146-0.464)\end{array}$ & $<0.001$ \\
\hline Early neurological deterioration & 13(12.3) & $59(38.8)$ & $\begin{array}{l}4.538 \\
(2.332-8.832)\end{array}$ & $<0.001$ & $\begin{array}{l}4.780 \\
(2.341-9.871)\end{array}$ & $<0.001$ \\
\hline
\end{tabular}

Values were measured for the peak body temperature within $24 \mathrm{~h}$ following mechanical thrombectomy

Abbreviations: $B T$ body temperature; $m R S$ modified Rankin Scale; OR odds ratio; $H T$ hemorrhage transformation; HI hemorrhagic infarction; SAH subarachnoid hemorrhage; $s / C H$ symptomatic intracranial hemorrhage

tThe multiple logistic regression test was used to analyze ORs. Adjusted variables: age, sex, length of stay, NIHSS score at baseline, atrial fibrillation, smoking, serum glucose level, SBP, WBC, procedure time, successful reperfusion and number of devices passes

₹The Bonferroni correction method was used to assess the primary and secondary outcomes, and a $P$ value $<0.05 /$ number of comparisons was used as the threshold for statistical significance $(P<0.025$ for primary outcomes and $P<0.008$ for secondary outcomes) 
0.006), higher WBC counts $(P=0.043)$ and longer procedure times $(P=0.020)$. There were no differences in terms of the pre-MT BT, arterial territory, or infection post-MT between the two groups.

\section{Association between the post-MT body temperature and clinical outcomes}

Table 2 showed the peak BT levels within $24 \mathrm{~h}$ after MT with different primary and secondary outcomes. Functional independence (mRS score of $0-2$; favorable outcome) was confirmed in $83(32.2 \%)$ patients (Table 2, Additional file 1: Figure S1). The proportion of patients with functional independence was significantly lower in the fever group $\left(23.0 \%\right.$ versus $45.3 \% ; P<0.001$ in the $x^{2}$ test). Similarly, the number of patients with excellent outcomes (mRS score of $0-1$ ) was also lower in the fever group $\left(13.8 \%\right.$ versus $31.1 \% ; P=0.001$ in the $X^{2}$ test; Table 2).

Regarding secondary outcomes, 3-month mortality occurred more often in the fever group ( $40.1 \%$ versus $17.0 \% ; P<0.001$ in the $X^{2}$ test). Despite similar rates of HT in the two groups $(48.0 \%$ versus $40.6 \% ; P=0.239$ in the $X^{2}$ test), the frequency of sICH was higher in the fever group $(27.0 \%$ versus $14.2 \% ; P<0.001)$. The frequency of early clinical improvement was significantly higher in the non-fever group (58.2\% versus $27.0 \%$; $P<$ 0.001 ), and early neurological deterioration was significantly lower in the non-fever group than in the fever group $(12.3 \%$ versus $38.8 \% ; P<0.001)$. No difference was noted in the BT level among patients with HT $(P=$ 0.236; Table 2).

In the multivariable analysis, we included adjustments for confounders, and higher BT levels showed a negative correlation with favorable outcomes (OR, 0.384; $95 \% \mathrm{CI}, 0.201-0.733 ; P=0.004$ ) and excellent outcomes (OR, 0.404; $95 \%$ CI, 0.200-0.817; $P=0.012$; Table 2). Higher BT levels were also significantly associated with increased 3-month mortality (OR, 3.087; $95 \% \mathrm{CI}, 1.552-6.135 ; P=0.001)$, sICH (OR, $2.357 ; 95 \%$ CI, $1.176-4.723 ; \quad P=0.016)$, and early neurological deterioration (OR, 4.780; $95 \%$ CI, 2.3419.871; $P<0.001)$. However, early clinical improvement was negatively associated with higher BT levels (OR, $0.260 ; 95 \% \mathrm{CI}, 0.146-0.464 ; P<0.001)$. In-hospital mortality did not differ between the two groups in the multivariable analysis $(P=0.073)$.

\section{Subgroups analyzed the predictive value of the body temperature for clinical outcomes post-MT}

As hyperpyrexia was an independent predictor of poststroke outcomes, we further performed a sensitivity analysis, which was based on different BT levels. BT $\geq$ $37.5^{\circ} \mathrm{C}$ was negatively correlated with favourable outcomes at 3 months compared with the reference group with $\mathrm{BT}<37.5^{\circ} \mathrm{C}$, irrespective of the precise $\mathrm{BT}$ level (Fig. 2). However, there was no statistically significant difference when $\mathrm{BT}$ was $\geq 38^{\circ} \mathrm{C}$ in terms of excellent outcomes or the rate of HT. Higher BT levels, especially $\mathrm{BT} \geq 38^{\circ} \mathrm{C}$, were associated with a significantly increased risk of mortality at 3 months (OR, 3.229; $95 \% \mathrm{CI}$, 1.393-7.485).

In the subgroup analysis, there was significant heterogeneity in the ORs for favorable outcomes associated with fever patients who had successful recanalization post-MT and those who did not (Fig. 3). There was no evidence of heterogeneity in the effect of BT levels due to other prespecified variables, such as the number of the devices passes and intravenous thrombolysis before MT.

Based on the above results, we further performed a subgroup analysis of BT levels between patients with good and poor outcomes according to the achieved recanalization status (Table 3). The results showed that patients with favorable outcomes had significantly lower BT levels than those with poor outcomes. Moreover, the difference was significant in patients with successful recanalization (TICI 2b-3) and complete recanalization (TICI 3). Additional file 2: Figure S2 showed the Kaplan-Meier analysis of patient survival rates. The non-fever group had significantly better survival rates than the fever group within $24 \mathrm{~h}$ after MT $(P<0.001 ; \log$-rank test).

\section{Body temperature, infection/antibiotic use, and 90-day clinical outcomes after MT}

Besides, more than $50 \%$ of patients who underwent MT developed fever within $24 \mathrm{~h}$. Given the close link between fever and infectious disease, we analyzed the incidence of infection/antibiotic use within $24 \mathrm{~h}$ and over $24 \mathrm{~h}$ after MT (Additional file 3: Table S1) and investigated the association between the infection diagnosis /antibiotic use during hospitalization and clinical outcomes (Additional file 4: Table S2).

Fifty-one patients were diagnosed with infection/antibiotic use within $24 \mathrm{~h}$ after MT. A total of 105 patients received a diagnosis with infection/antibiotics over $24 \mathrm{~h}$ post-MT. The main types of infection were pneumonia and urinary tract infection. Piperacillin-tazobactam was the most used antibiotic. Among patients with a fever within $24 \mathrm{~h}$ post-MT who were not diagnosed with infection, $36.8 \%$ were diagnosed with an infection over a further $24 \mathrm{~h}$. Table S2 showed that infection within $24 \mathrm{~h}$ after MT had a significant effect on the favorable outcome $(P=0.032)$. On the contrary, infection beyond $24 \mathrm{~h}$ had no effect on the favorable outcome $(P=0.066)$.

\section{Discussion}

Our results showed that increasing peak BT levels within $24 \mathrm{~h}$ post-MT were associated with a higher likelihood of 3-month mortality and lower odds of functional 


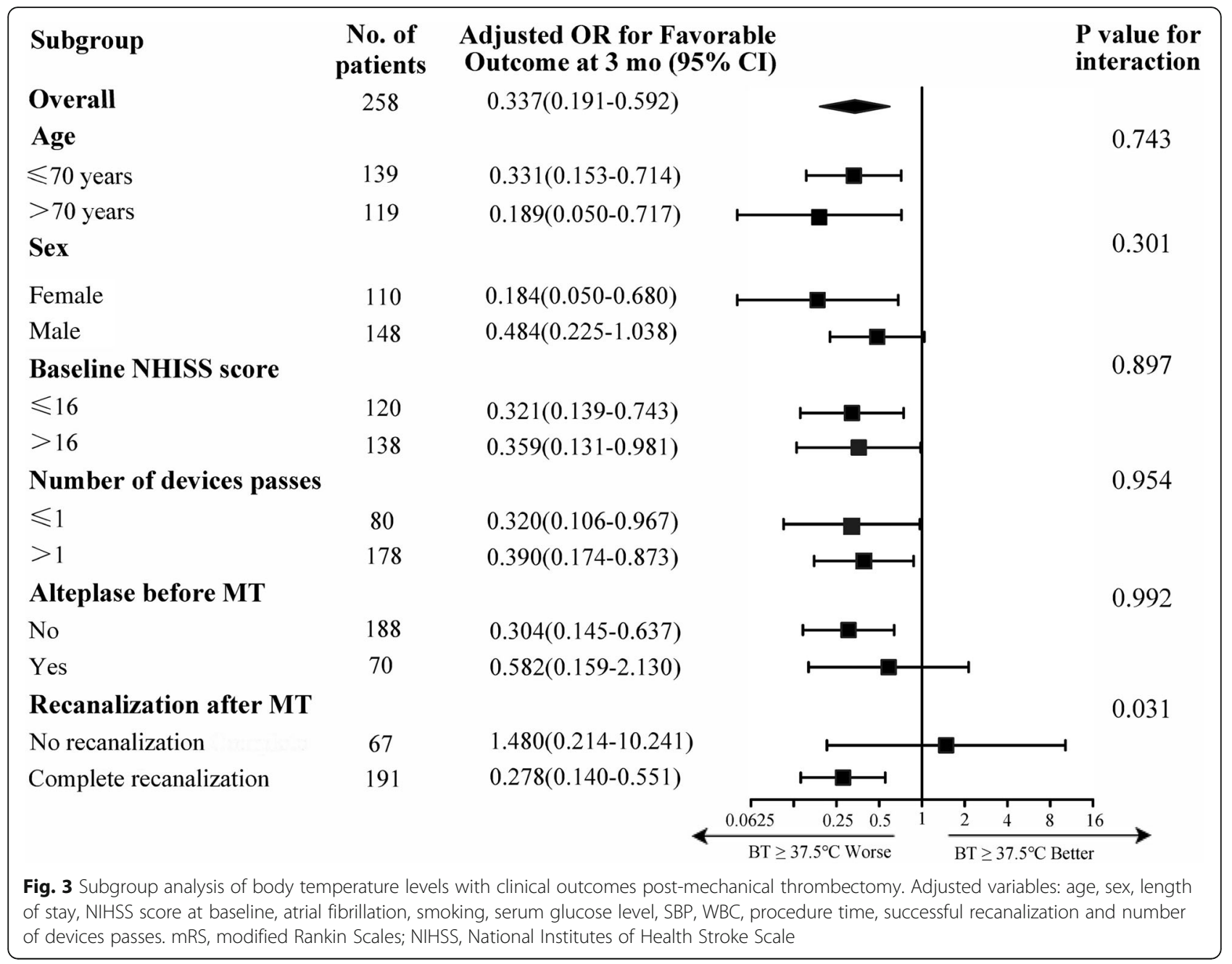

independence. These associations were independent of the age, sex, length of stay, NIHSS score at baseline, atrial fibrillation, smoking, serum glucose level, SBP, WBC, procedure time, successful recanalization, and number of the devices passes. The chance of a good outcome was halved, and the risk of death was increased four-fold when BT was $\geq 38^{\circ} \mathrm{C}$. However, there was no association between the BT level and the risk of HT. Currently, there are few studies on the relationship between BT levels and clinical prognosis post-MT, especially the effects on recanalization statuses and survival rates. Therefore, this study may provide a basis for future studies on the correlation of fever post-MT and clinical outcomes.

Table 3 Comparison of different BT levels in subgroup analysis according to the achieved recanalization status

\begin{tabular}{|c|c|c|c|c|c|c|c|c|c|}
\hline \multirow[b]{2}{*}{ Patient group } & \multicolumn{2}{|l|}{$\mathrm{TICl}<2 \mathrm{~b}$} & \multirow[b]{2}{*}{ Pvalue } & \multicolumn{2}{|l|}{$\mathrm{TICl} \geq \mathbf{2 b}$} & \multirow[b]{2}{*}{ Pvalue } & \multicolumn{2}{|l|}{$\mathrm{TICl}=3$} & \multirow[b]{2}{*}{ Pvalue } \\
\hline & mRS 0-2 & mRS 3-6 & & mRS 0-2 & mRS 3-6 & & mRS 0-2 & mRS 3-6 & \\
\hline $\bar{N}$ & 11 & 56 & & 79 & 112 & & 62 & 95 & \\
\hline Pre-MT BT $\left({ }^{\circ} \mathrm{C}\right)$ & $36.5(0.13)$ & $36.5(0.36)$ & 0.875 & $36.5(0.24)$ & $36.5(0.25)$ & 0.736 & $36.5(0.25)$ & $36.5(0.24)$ & 0.947 \\
\hline 6 h BT $\left({ }^{\circ} \mathrm{C}\right)$ & $37.0(0.60)$ & $37.2(0.94)$ & 0.677 & $36.7(0.39)$ & $37.0(0.78)$ & 0.058 & $36.7(0.34)$ & $37.0(0.76)$ & 0.026 \\
\hline 12 h BT $\left({ }^{\circ} \mathrm{C}\right)$ & $37.1(0.64)$ & $37.2(0.74)$ & 0.709 & $36.8(0.41)$ & $37.2(0.81)$ & $<0.001$ & $36.7(0.37)$ & $37.2(0.78)$ & $<0.001$ \\
\hline 24 h BT $\left({ }^{\circ} \mathrm{C}\right)$ & $37.1(0.58)$ & $37.3(0.60)$ & 0.319 & $36.9(0.54)$ & $37.3(0.71)$ & $<0.001$ & $36.8(0.53)$ & $37.3(0.69)$ & $<0.001$ \\
\hline Peak 24-hour BT $\left({ }^{\circ} \mathrm{C}\right)$ & $37.9(0.46)$ & $37.8(0.68)$ & 0.753 & $37.3(0.51)$ & $37.7(0.65)$ & $<0.001$ & $37.2(0.49)$ & $37.7(0.61)$ & $<0.001$ \\
\hline
\end{tabular}

All values were expressed as the mean(SD)

Abbreviations: $B T$ body temperature; $N$ number; $T I C l$ thrombolysis in cerebral infarction; $m R S$ modified Rankin Scale 
By previous studies, hyperpyrexia has an adverse effect on functional outcomes in patients treated with tissuetype plasminogen activator (t-PA) $[25,26]$. However, the potential adverse effects of fever associated with early reperfusion can be better studied after MT, since the successful reperfusion rate of MT is higher than that of intravenous t-PA $[13,14]$. Another study reported that patients with a higher baseline BT had less severe neurological deficits and smaller infarct volumes [11]. Part of our results were in accordance with a recent study on the association between BT and outcomes in patients treated with MT, and researchers believed that increased BT both before and after MT worsened the prognosis of patients [27]. In contrast to the referenced study [27], our results showed a few differences. First, in the present study, when excluding patients with acute infection at admission, we found that pre-MT BT levels did not affect functional outcomes and survival rates. The vast majority of patients in our study had normal baseline BT levels on admission. Furthermore, we excluded patients with an acute infection on admission, which may have led to the differences from the previous study. Second, our results showed that upon a priori dichotomizing all patients according to the definite recanalization status (TICI of $0-2 b$ versus TICI of $2 b-3$ ), hyperpyrexia had a greater impact on successful recanalization patients treated with MT than those who did not, demonstrating the need for individualized treatment of patients with different recanalization statuses. However, the underlying mechanisms are unclear and need to be further studied.

A preclinical study has shown that hypothermia therapy confers greater protective effects [28]. However, clinical trials have failed to demonstrate the benefit of therapeutic hypothermia. The Cooling for Ischemic Stroke Trial (COOLIST) was a multicenter randomized controlled trial that showed that surface cooling is not feasible below $35{ }^{\circ} \mathrm{C}$, and mild hypothermia could lead to pneumonia, which offset the benefits of hypothermia therapy [10]. Therefore, maintenance of a normal BT is more feasible and safer than hypothermia treatment. Also, this study showed different effects on functional outcomes according to BT levels. In the subgroup analysis, an association between lower BT levels and better clinical outcomes was observed in the successful recanalization group $(P<0.001)$ but not in the nonrecanalization group. Thus, our results support that further investigation of early BT control in patients with hyperpyrexia, especially patients with successful recanalization and $\mathrm{BT} \geq 37.5^{\circ} \mathrm{C}$, is warranted. Future research should investigate the association between early hypothermia therapy and infarct volumes and whether mild hypothermia benefits poststroke recovery in patients with successful recanalization undergoing endovascular therapy.
In this study, more than half of the patients who underwent MT developed a fever. Previous studies have demonstrated that age, stroke severity, stroke type, lesion volume, infection, and inflammatory response may be determinants of fever after AIS [29-31]. Other causes are hospital-acquired infections and complications such as deep vein thrombosis [32]. Given the strong relationship between fever and infection, we analyzed the relationships between fever, infection/antibiotic use at different time points and clinical outcomes at 90 days after AIS. The results showed that 156 patients $(60.4 \%)$ were diagnosed with the infection. Infection within $24 \mathrm{~h}$ after MT was associated with poor 3-month outcome. However, infection was not a factor that affected favorable outcome 90 days over $24 \mathrm{~h}$ after MT. These findings lend further support to the hypothesized detrimental influence of temperature elevation on the fate of ischemic tissues in the early aftermath of cerebrovascular injury, which were consistent with the research results of Nowak et al. [33]. Several recent clinical trials tested preventive antibiotic therapy could reduce the occurrence of post-AIS infection and provided additional benefits over standard treatment [34, 35]. Therefore, when necessary, prophylactic use of antibiotics should be given to patients at risk of infection to reduce the incidence of post-MT infection. Patients under general anesthesia have a higher risk of infection after endovascular treatment $[36,37]$. Thus, for patients who can protect their airway and are cooperative, local anesthesia with conscious sedation of AIS are feasible to short anesthesia time, operation time, which can reduce the chance of iatrogenic infections during MT. More importantly, using comprehensive treatment measures to maintain normal BT, rather than hyperthermia or hypothermia treatment, is more beneficial to patients' long-term clinical outcomes.

There are some limitations in this study. First, we evaluated the effect of BT on outcomes for a limited duration of time, and the impact of BT during MT and BT variability were not assessed in the study, although we analyzed the effects of pre-MT and post-MT body temperature levels. Second, only patients who had undergone MT were included, without considering those who underwent other types of procedures, such as arterial stenting or balloon dilatation angioplasty. In addition, although we excluded patients with possible infection and patients with severe circulatory or respiratory failure or malignant tumors at admission, the effects of drug factors on BT were not fully assessed. Additionally, although we adjusted for possible confounding variables, several risk factors, such as physical activity, socioeconomic status was not analyzed. Finally, we did not estimate the final infarct size. It was proven that a higher BT at $24 \mathrm{~h}$ after stroke was associated with a greater 
hypodensity volume and worse outcomes in AIS patients treated with thrombolytic therapy [25]. Exploring infarct sizes may provide an important basis for finding the cause of hyperthermia in patients. Further large, welldesigned studies including measurements of infarct size are required to better characterize the underlying relationships between the infarct size, BT levels, and clinical outcomes.

\section{Conclusions}

In summary, our findings provide preliminary data on the relationship between post-MT hyperpyrexia and clinical outcomes, especially when $\mathrm{BT} \geq 38^{\circ} \mathrm{C}$. Post-MT hyperpyrexia is an independent predictor of 3-month functional independence and mortality and may augment the risk of sICH and early neurological deterioration, particularly in those with successful recanalization. Therefore, it is essential to assess the early temperature of post-MT patients for the risk of adverse clinical outcomes and mortality. The results encourage prospective studies to investigate the robust potential benefits of post-MT recovery in patients with lower BT levels.

\begin{abstract}
Abbreviations
AIS: Acute ischemic stroke; RCT: Randomized controlled clinical trial; MT: Mechanical thrombectomy; LVO: Large vessel occlusion; BT: Body temperature; mRS: Modified Rankin scale; WBC: White blood cell; CRP: Creaction protein; $C T$ : Computerized tomography; $C T A$ : $C$ T angiography; SBP: Systolic blood pressure; DBP: Diastolic blood pressure; DM: Diabetes mellitus; TOAST: Trial of ORG 10172 in Acute Stroke Treatment; NIHS S: National Institute of Health Stroke Scale; ASPECTs: Alberta Stroke Program Early CT Score; TICl: Thrombolysis in cerebral infarction; sICH: Symptomatic intracranial hemorrhage; HT: Hemorrhage transformation; HI: Hemorrhagic infarction; SAH: Subarachnoid hemorrhage; ORs: Odds ratios; Cl: Confidence interval; IQR: Interquartile range; TIA: Transient ischemic attack; LDL-C: Lowdensity lipoprotein cholesterol; HDL-C: High-density lipoprotein cholesterol; ICA: Internal carotid artery; MCA: Middle cerebral artery
\end{abstract}

\section{Supplementary Information}

The online version contains supplementary material available at https://doi. org/10.1186/s12883-021-02400-8.

Additional file 1: Supplementary Figure S1. Distribution of modified Rankin Scale (mRS) scores at 3 months in each group (OR, 0.361; $95 \% \mathrm{Cl}$, $0.211-0.619 ; P<0.001)$. BT, body temperature.

Additional file 2: Supplementary Figure S2. Kaplan-Meier survival curve at different time points compared between the fever group (BT $\geq$ $\left.37.5^{\circ} \mathrm{C}\right)$ and non-fever group $\left(\mathrm{BT}<37.5^{\circ} \mathrm{C}\right)$ at baseline $(\mathrm{A})$, body temperatures $6 \mathrm{~h}$ post-MT (B), body temperatures $12 \mathrm{~h}$ post-MT(C), and peak body temperatures within $24 \mathrm{~h}$ post-MT(D). P-values were derived using the log-rank test.

Additional file 3: Supplementary Table S1. Distribution of BT at 24h post-MT with diagnosed infection/antibiotics use during the entire course of hospitalization.

Additional file 4: Supplementary Table S2. Relationships between diagnosis of infection/antibiotics use and clinical outcomes at different time points after MT.

\section{Acknowledgements}

We thank all the participants of the study, and our colleagues at the Department of Neurology at West China Hospital of Sichuan University.

\section{Authors' contributions}

$\mathrm{MC}$ and JF drafted and revised the manuscript, contributed equally to this work. XW was responsible for the manuscript revision. QL collected data and followed up with the patients. LH and LF conceived and designed the study, and approved the final manuscript. The author(s) read and approved the final manuscript.

\section{Funding}

This work was supported by the National Key R\&D Program of China (Grant number: 2018YFC1311400 and 2018YFC1311401), Science \&Technology Department of Sichuan Province (Grant number: 2020YFS0155), and West China Nursing Discipline Special Fund Project, Sichuan University (Grant number: HXHL20021). The funding sources had no involvement during the conduction of the research.

Availability of data and materials

Data are available upon reasonable request.

\section{Declarations}

\section{Ethics approval and consent to participate}

This study protocol was approved by the Local Ethics Committee of West China Hospital, Sichuan University (No:2019[319]). As this was a retrospective study, written informed consent was not required.

\section{Consent for publication}

Not applicable.

\section{Competing interests}

The authors declare no conflict of interest.

Received: 7 December 2020 Accepted: 14 September 2021

Published online: 21 September 2021

\section{References}

1. Barthels D, Das H. Current advances in ischemic stroke research and therapies. Biochim Biophys Acta Mol Basis Dis. 2020;1866(4):165260.

2. Bracard S, Ducrocq X, Mas $J$, Soudant M, Oppenheim C, Moulin T, Guillemin F. THRACE investigators. Mechanical thrombectomy after intravenous alteplase versus alteplase alone after stroke (THRACE): a randomised controlled trial. Lancet Neurol. 2016;15(11):1138-47.

3. Yang P, Zhang Y, Zhang L, Zhang Y, Treurniet KM, Chen W, et al. Endovascular Thrombectomy with or without Intravenous Alteplase in Acute Stroke. N Engl J Med. 2020;382(21):1981-93.

4. Turk AS 3rd, Siddiqui A, Fifi JT, De Leacy RA, Fiorella DJ, Gu E, et al. Aspiration thrombectomy versus stent retriever thrombectomy as first-line approach for large vessel occlusion (COMPASS): a multicentre, randomised, open label, blinded outcome, non-inferiority trial. Lancet. 2019;393(10175): 998-1008.

5. Powers WJ, Rabinstein AA, Ackerson T, Adeoye OM, Bambakidis NC, Becker K, et al. 2018 Guidelines for the Early Management of Patients With Acute Ischemic Stroke: A Guideline for Healthcare Professionals From the American Heart Association/American Stroke Association. Stroke. 2018;49(3): 46-110.

6. Goyal M, Menon BK, van Zwam WH, Dippel DW, Mitchell PJ, Demchuk AM, et al. Endovascular thrombectomy after large-vessel ischaemic stroke: a meta-analysis of individual patient data from five randomised trials. Lancet. 2016;387(10029):1723-31.

7. Goyal M, Demchuk AM, Menon BK, Eesa M, Rempel JL, Thornton J, et al. Randomized assessment of rapid endovascular treatment of ischemic stroke. N Engl J Med. 2015;372(11):1019-30.

8. Saxena M, Young P, Pilcher D, Bailey M, Harrison D, Bellomo R, et al. Early temperature and mortality in critically ill patients with acute neurological diseases: trauma and stroke differ from infection. Intensive Care Med. 2015; 41(5):823-32.

9. van der Worp HB, Sena ES, Donnan GA, Howells DW, Macleod MR. Hypothermia in animal models of acute ischaemic stroke: a systematic review and meta-analysis. Brain. 2007;130:3063-74

10. Geurts M, Petersson J, Brizzi M, Olsson-Hau S, Luijckx GJ, Algra A, et al. COOLIST (Cooling for Ischemic Stroke Trial): A Multicenter, Open, Randomized, Phase II, Clinical Trial. Stroke. 2017;48(1):219-21. 
11. Kim SH, Saver JL. Initial body temperature in ischemic stroke: nonpotentiation of tissue-type plasminogen activator benefit and inverse association with severity. Stroke. 2015;46(1):132-6.

12. Tiainen M, Meretoja A, Strbian D, Suvanto J, Curtze S, Lindsberg PJ, et al. Body temperature, blood infection parameters, and outcome of thrombolysis-treated ischemic stroke patients. Int J Stroke. 2013;8(8):632-8.

13. Campbell BCV, Mitchell PJ, Churilov L, Yassi N, Kleinig TJ, Dowling RJ, et al. Tenecteplase versus Alteplase before Thrombectomy for Ischemic Stroke. N Engl J Med. 2018;378(17):1573-82.

14. Bhatia R, Hill MD, Shobha N, Menon B, Bal S, Kochar P, et al. Low rates of acute recanalization with intravenous recombinant tissue plasminogen activator in ischemic stroke: real-world experience and a call for action. Stroke. 2010;41(10):2254-8.

15. Jang WJ, Yang JH, Song YB, Chun WJ, Oh JH, Park YH, et al. Clinical Significance of Postinfarct Fever in ST-Segment Elevation Myocardial Infarction: A Cardiac Magnetic Resonance Imaging Study. J Am Heart Assoc. 2017;6(4):005687.

16. Goyal N, Tsivgoulis G, Iftikhar S, Khorchid Y, Fawad Ishfaq M, Doss VT, et al. Admission systolic blood pressure and outcomes in large vessel occlusion strokes treated with endovascular treatment. J Neurointerv Surg. 2017;9(5): 451-4.

17. Elijovich L, Goyal N, Mainali S, Hoit D, Arthur AS, Whitehead M, Choudhri AF. CTA collateral score predicts infarct volume and clinical outcome after endovascular therapy for acute ischemic stroke: a retrospective chart review. J Neurointerv Surg. 2016;8(6):559-62.

18. Axelrod YK, Diringer MN. Temperature management in acute neurologic disorders. Neurol Clin. 2008:26(2):585-603.

19. Barber PA, Demchuk AM, Zhang J, Buchan AM. Validity and reliability of a quantitative computed tomography score in predicting outcome of hyperacute stroke before thrombolytic therapy. ASPECTS Study Group. Alberta Stroke Programme Early CT Score. Lancet. 2000;355(9216):1670-4.

20. Higashida RT, Furlan AJ, Roberts H, Tomsick T, Connors B, Barr J, et al. Trial design and reporting standards for intra-arterial cerebral thrombolysis for acute ischemic stroke. Stroke Stroke. 2003;34(8):e109-37.

21. Hacke W, Kaste M, Bluhmki E, Brozman M, Dávalos A, Guidetti D, et al. Thrombolysis with alteplase 3 to 4.5 hours after acute ischemic stroke. N Engl J Med. 2008;359(13):1317-29.

22. Fu J, Zhou Y, Li Q, Zhong G, Zhang S, Zhang R, et al. Perfusion Changes of Unexplained Early Neurological Deterioration After Reperfusion Therapy. Transl Stroke Res. 2020;11(2):195-203.

23. Yu WM, Abdul-Rahim AH, Cameron AC, Kõrv J, Sevcik P, Toni D, et al. The Incidence and Associated Factors of Early Neurological Deterioration After Thrombolysis: Results From SITS Registry. Stroke. 2020;51(9):2705-14.

24. Choi KH, Kim JH, Kang KW, Kim JT, Choi SM, Lee SH, et al. HbA1c (Glycated Hemoglobin) Levels and Clinical Outcome Post-Mechanical Thrombectomy in Patients With Large Vessel Occlusion. Stroke. 2018: STROKEAHA118021598.

25. Dehkharghani S, Bowen M, Haussen DC, Gleason T, Prater A, Cai Q, et al. Body Temperature Modulates Infarction Growth following Endovascular Reperfusion. AJNR Am J Neuroradiol. 2017;38(1):46-51.

26. Dehkharghani S, Yaghi S, Bowen MT, Pisani L, Scher E, Haussen DC, Nogueira RG. Mild fever as a catalyst for consumption of the ischaemic penumbra despite endovascular reperfusion. Brain Commun. 2020;2(2): fcaa116.

27. Diprose WK, Liem B, Wang MTM, Sutcliffe JA, Brew S, Caldwell JR, et al. Impact of Body Temperature Before and After Endovascular Thrombectomy for Large Vessel Occlusion Stroke. Stroke. 2020;51(4):1218-25.

28. Krieger DW, Yenari MA. Therapeutic hypothermia for acute ischemic stroke: what do laboratory studies teach us? Stroke. 2004;35(6):1482-9.

29. He Z, Yamawaki T, Yang S, Day AL, Simpkins JW, Naritomi H. Experimental model of small deep infarcts involving the hypothalamus in rats: changes in body temperature and postural reflex. Stroke. 1999;30:2743-51.

30. Leira R, Rodriguez-Yanez M, Castellanos M, Blanco M, Nombela F, Sobrino T, et al. Hyperthermia is a surrogate marker of inflammation mediated cause of brain damage in acute ischemic stroke. J Int Med. 2006;260:343-9.

31. Emsley HCA, Smith CJ, Tyrrell PJ, Hopkins SJ. Inflammation in acute ischemic stroke and its relevance to stroke critical care. Neurocrit Care. 2008;9:125-38.

32. Georgilis K, Promaritoglou A, Dafni U, Bassiakos Y, Vemmos K. Aetiology of fever in patients with acute stroke. J Intern Med. 1999;246:203-9.
33. Nowak K, Derbisz J, Pęksa J, Łasocha B, Brzegowy P, Slowik J, et al. Poststroke infection in acute ischemic stroke patients treated with mechanical thrombectomy does not affect long-term outcome. Postepy Kardiol Interwencyjnej. 2020;16(4):452-9.

34. Hetze S, Engel O, Römer C, Mueller S, Dirnagl U, Meisel C, et al. Superiority of preventive antibiotic treatment compared with standard treatment of poststroke pneumonia in experimental stroke: a bed to bench approach. J Cereb Blood Flow Metab. 2013;33(6):846-54.

35. Kalra L, Irshad S, Hodsoll J, Simpson M, Gulliford M, Smithard D, et al. Prophylactic antibiotics after acute stroke for reducing pneumonia in patients with dysphagia (STROKE-INF): a prospective, cluster-randomised, open-label, masked endpoint, controlled clinical trial. Lancet. 2015; 386(10006):1835-44.

36. Talke PO, Sharma D, Heyer EJ, Bergese SD, Blackham KA, Stevens RD. Republished: Society for Neuroscience in Anesthesiology and Critical Care expert consensus statement: Anesthetic management of endovascular treatment for acute ischemic stroke. Stroke. 2014;45(8):e138-50.

37. Sharma D, Rasmussen M, Han R, Whalin MK, Davis M, Kofke WA, et al. Anesthetic Management of Endovascular Treatment of Acute Ischemic Stroke During COVID-19 Pandemic: Consensus Statement From Society for Neuroscience in Anesthesiology \& Critical Care (SNACC): Endorsed by Society of Vascular \& Interventional Neurology (SVIN), Society of Neurolnterventional Surgery (SNIS), Neurocritical Care Society (NCS), European Society of Minimally Invasive Neurological Therapy (ESMINT) and American Association of Neurological Surgeons (AANS) and Congress of Neurological Surgeons (CNS) Cerebrovascular Section. J Neurosurg Anesthesiol. 2020;32(3):193-201.

\section{Publisher's Note}

Springer Nature remains neutral with regard to jurisdictional claims in published maps and institutional affiliations.
Ready to submit your research? Choose BMC and benefit from:

- fast, convenient online submission

- thorough peer review by experienced researchers in your field

- rapid publication on acceptance

- support for research data, including large and complex data types

- gold Open Access which fosters wider collaboration and increased citations

- maximum visibility for your research: over $100 \mathrm{M}$ website views per year

At BMC, research is always in progress.

Learn more biomedcentral.com/submissions 